\title{
Transformación de usos agrícolas tradicionales en superficies construidas. Cambios en los usos y coberturas del suelo en el municipio de Valencia (1956-2012)
}

\section{Conversion of traditional agricultural land to built-up areas. Land use/cover changes in the municipality of Valencia (1956-2012)}

\author{
Antonio Valera Lozano, Carlos Añó Vidal y Juan Sánchez Díaz ${ }^{1}$
}

\begin{abstract}
RESUMEN
El objetivo principal de este artículo es analizar la dinámica espacial y temporal de los usos y coberturas del suelo entre 1956 y 2012 en Valencia. El área de estudio es un ejemplo paradigmático de las intensas transformaciones experimentadas en los llanos aluviales mediterráneos. Mediante la fotointerpretación de fotografías aéreas de distintas fechas $(1956,1984,2006$ y 2012) y análisis cartográfico con SIG, se han establecido los cambios a escala detallada (1:10.000). Los resultados muestran el crecimiento de las superficies construidas sobre el resto de usos. En 1956 las superficies agrícolas y naturales ocupaban un total de 11.112 hectáreas. A lo largo de cincuenta y cinco años, se han sellado 2.396 hectáreas. En 2012 la superficie construida suponía el 33\% del área de estudio. Hay que destacar que en el municipio de Valencia la mayor parte de los suelos urbanizados han sustituido a tierras agrícolas de alta capacidad productiva.
\end{abstract}

\footnotetext{
${ }^{1}$ Departamento de Planificación Territorial, Centro de Investigaciones sobre Desertificación - CIDE (Consejo Superior de Investigaciones Científicas - Universitat de València - Generalitat Valenciana), Carretera Moncada-Náquera, Km 4,5, Apartado Oficial 46113 Moncada, Valencia. Tel.963424162.E-mail: antonio.valera@uv.es, carlos.anyo@uv.es, juan.sanchez@uv.es.
} 
Palabras Clave: cambios de uso/cobertura del suelo; crecimiento urbano; consumo de suelo; suelos de elevada calidad agrícola; llanos aluviales mediterráneos.

\begin{abstract}
The aim of this study is to understand the land use-cover dynamics from the mid1950s to 2012 in the municipality of Valencia, eastern Spain. The study area is a very interesting example of the many land use and land cover changes in the landscape of Mediterranean alluvial plains. The analysis was based on photo interpretation of aerial photographs (1956, 1984, 2006 and 2012) and GIS based methodology. At a detailed scale $(1: 10,000)$, results show that there has been a highly dynamic process produced by the extent of land developed as urban area. In 1956 11,112 hectares were occupied by agricultural land and natural areas. During fifty five years, the sealed surface was 2,396 hectares. In 2012 the built-up extent was around 33\% of the studied area. In the municipality of Valencia much of the land converted to urban use was once highly productive agricultural land.
\end{abstract}

KEY WORDS: land use and land cover changes; urban growth; land taken; high quality agricultural soils; Mediterranean alluvial plains.

\title{
INTRODUCCIÓN
}

En España, desde la década de 1950, entre los procesos que más han influido en los cambios experimentados por los usos y coberturas del suelo destacan la extensión e intensificación de los cultivos de regadío, el abandono de áreas agrícolas tradicionales y de tierras marginales que permitirán la posterior restauración pasiva o activa de la vegetación, y el aumento tanto de la superficie urbanizada como del sellado del medio edáfico (Serra et al., 2008, 2014; Lasanta et al., 2014). Entre las amenazas medioambientales provocadas por los cambios de uso del suelo sobresalen el impacto en la biodiversidad por la modificación y fragmentación de hábitats o la pérdida de especies (Martínez Fernández et al., 2015); las repercusiones en el cambio climático (alteración del ciclo del carbono, emisión de gases de efecto invernadero, etc.); la contaminación del aire, agua y suelos o la degradación de tierras por erosión, compactación, contaminación, salinización o sellado antropogénico (EEA, 2010).

En las últimas décadas la Comunitat Valenciana ha experimentado un fuerte crecimiento demográfico y económico que ha ocasionado importantes modificaciones en las estructuras productivas tradicionales, así como un acelerado proceso de urbanización. Gran parte de estas transformaciones se han localizado, al igual que en gran parte de la franja mediterránea, en las áreas 
urbanas litorales, principalmente en los centros metropolitanos que concentran los efectivos poblacionales, las actividades económicas y las principales infraestructuras y equipamientos. Estos cambios han tenido una clara plasmación en la dinámica experimentada por los usos del suelo, contribuyendo los factores económicos a acelerar las modificaciones y agudizar la competencia entre las diferentes utilizaciones del territorio, incompatibles entre sí, que acabarán afectando a la fisonomía, estructura y funcionalidad del paisaje agrario heredado.

El municipio de Valencia es, con diferencia, el primero en importancia demográfica dentro de la Comunitat Valenciana y el segundo del litoral mediterráneo español. En 2014 se contabilizan 786.424 habitantes en las 13.465 ha de su término municipal, de las cuales 5.719 ha se incluyen dentro del Parque Natural de l'Albufera. Una característica particular de la ciudad de Valencia es la estrecha relación simbiótica con el espacio agrícola que la rodea y la ha sostenido durante siglos (Puncel, 1999; Furió, 2012). Es quizá esa valoración de la actividad agrícola intensiva una de las principales causas del tradicional carácter denso y concentrado de la ciudad de Valencia en contraposición con otras áreas urbanas. Tradicionalmente ha existido una importante dualidad entre los espacios agrícolas de regadío intensivo de la huerta y el arrozal, y las superficies construidas ligadas al elevado volumen poblacional y a las funciones urbanas que ha ostentado por su capitalidad regional. Más allá de la ampliación de áreas de arrozal en torno a l'Albufera desde el siglo XVIII (Sanchis, 2007), y la gran expansión de la ciudad sobre el espacio extramuros en el XIX y principios del Xx, durante los últimos 50 años se ha producido un importante proceso de crecimiento urbano que ha aislado y reducido progresivamente los cultivos hortícolas tradicionales.

En Valencia las características del medio natural en general, y del suelo en particular, se corresponden con las de mejor aptitud para el uso agrario. La progresiva antropización, al modificar las propiedades edáficas iniciales, ha determinado en gran medida la calidad y productividad de los suelos, propiciando, tanto en el pasado como en la actualidad, su utilización agrícola intensiva, actividad que conforma un legado cultural e histórico en armonía con un paisaje agrario excepcional en Europa. En el Informe Dobrís, la Agencia Europea del Medio Ambiente destacaba que, dentro de su clasificación de paisajes europeos, únicamente quedaban seis espacios de horticultura tradicional: tres en Italia, dos en España (las huertas de Valencia y Murcia) y uno en Grecia (AEMA, 1998).

El objetivo de este artículo es realizar un análisis pormenorizado del proceso de cambio de usos y coberturas del suelo en el municipio de Valencia. 
Para ello son necesarias cartografías a escala detallada y con una cierta amplitud temporal. Las series cartográficas disponibles hasta el momento que cumplen este requisito de escala son únicamente las generadas dentro del Sistema de Información sobre la Ocupación del Suelo en España - SIOSE para la Comunitat Valenciana (Membrado, 2011; IGN, 2011). Para fechas anteriores a 2005 la única información existente corresponde al proyecto CORINE Land Cover, aunque a escala poco detallada (1:100.000) y limitada a 1990 y 2000. En este trabajo, por tanto, se ha generado una serie cartográfica de usos y coberturas del suelo a escala 1:10.000 para la segunda mitad del siglo xx y primera década del xxi. La metodología, escala de trabajo y las características de la leyenda cartográfica ( 3 niveles jerárquicos) son similares a las aplicadas en el estudio del municipio de Elx (Valera et al., 2011). A continuación se analiza la dinámica espacial y temporal de los usos y coberturas del suelo en Valencia entre 1956 y 2012, aportando también dos fechas intermedias (1984 y 2006). Para esas mismas fechas y periodos entre ellas, se presentan y analizan también los datos y tendencias aportados por los resultados de distintos indicadores. La información obtenida en este trabajo, tanto datos primarios, como indicadores territoriales y cartografías asociadas, permiten conocer de forma pormenorizada la dinámica de las transformaciones acaecidas y las posibles causas y consecuencias de estos cambios.

\section{MATERIALES Y MÉTODOS}

A partir de imágenes correspondientes a las fechas de 1956, 1984, 2006 y 2012, y utilizando métodos de análisis cartográfico con SIG, se han obtenido los cambios acumulativos de los usos y coberturas del suelo a escala detallada. Los fotogramas de los vuelos de 1956 y 1984, obtenidos originalmente por el Ejército del Aire (CECAF) a una escala de 1:33.000 y 1:30.000 respectivamente, fueron escaneados a alta resolución y ortorrectificados para su fotointerpretación a escala 1:10.000. La ortorrectificación se realizó identificando puntos de control sobre un modelo digital de elevaciones y dos ortofotos de 2006 y 2012. Así, se obtuvieron ortofotografías digitales georreferenciadas y sin deformaciones. El mapa topográfico digital, escala 1:10.000, del Instituto Cartográfico Valenciano constituyó la base de referencia cartográfica para la incorporación de la información aportada por las imágenes de 1956, 1984, 2006 y 2012. En el cuadro 1 se detallan las principales características de las imágenes utilizadas. A partir de las imágenes en formato ráster, se realizó, mediante técnicas convencionales de fotointerpretación, la digitalización vecto- 
rial en pantalla teniendo en cuenta la tipología de usos y coberturas del suelo. La leyenda cartográfica propuesta para el municipio de Valencia está estructurada en 3 niveles jerárquicos, en los que las cuatro clases principales a nivel 1 se subdividen, respectivamente, en 13 y 27 clases a nivel 2 y 3 . Un ejemplo de aplicación de los niveles de leyenda puede visualizarse en la figura 1.

\section{Cuadro 1}

CARACTERÍSTICAS DE LAS IMÁGENES UTILIZADAS

\begin{tabular}{ccc}
\hline Fecha & Organismo & Escala media/Resolución \\
\hline 1956 & Ejército del Aire (CECAF) & $1: 33.000$ \\
1984 & Ejército del Aire (CECAF) & $1: 30.000$ \\
2006 & Instituto Cartográfico Valenciano & Ortofoto digital: \\
& (ICV) & $0,5 \times 0,5$ m. por píxel \\
2012 & Plan Nacional de Ortofotografía & Ortofoto digital: \\
& Aérea (PNOA) & $0,25 \times 0,25$ m. por píxel \\
\hline
\end{tabular}

FIGURA 1

EJEMPLO DE APLICACIÓN DE DIFERENTES NIVELES DE LEYENDA AL SUDOESTE DE LA CIUDAD

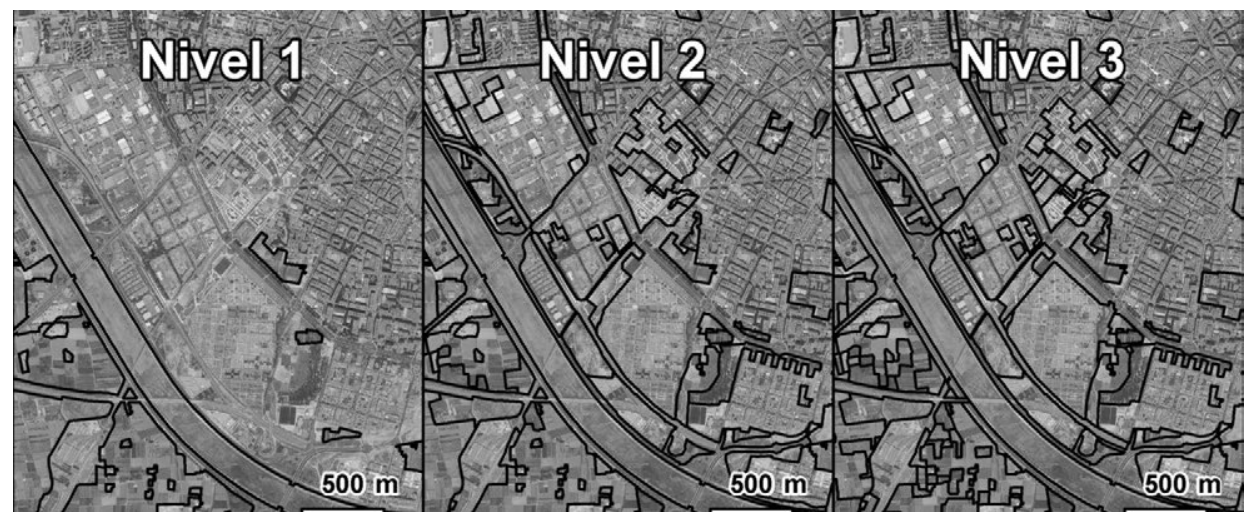

Las líneas en negro corresponden a la delimitación de usos. 
La extracción de la información se efectuó en dos niveles. En primer lugar, se realizó la base de datos geométricos, proceso de digitalización vectorial, teniendo en cuenta las clases de usos y coberturas del suelo. Con este fin, se digitalizaron en pantalla las unidades identificables en la ortofoto más reciente (2012). A partir de ellas, se construyó una topología de polígono arco y se asignó un identificador numérico a cada unidad. En segundo lugar, se construyeron las tablas de bases de datos asociadas, asignándose los identificadores de las tipologías de uso a los polígonos digitalizados. Las cartografías para las fechas anteriores se realizaron progresivamente mediante la adición, la sustracción de elementos o la modificación de atributos de la capa correspondiente a la fecha inmediatamente posterior disponible. Este procedimiento permite minimizar desplazamientos irreales en las cartografías que puedan ser contabilizados en el análisis como falsos cambios (Thompson et al., 2007). La información fue revisada y corregida en gabinete y en campo. Se obtuvieron los resultados absolutos y relativos para cada clase en las distintas fechas analizadas y se realizó el intersecado de las capas para obtener matrices de cambio de los usos del suelo entre los distintos periodos. En los cálculos se ha considerado sólo la superficie municipal en 1956, dejando de lado el área de crecimiento de muelles y espigones del puerto.

La información sobre la capacidad agrológica del medio edáfico proviene del proyecto "Capacidad de Uso del Suelo como Recurso Natural en la Comunidad Valenciana", realizado a inicios de los años 90 del siglo pasado a escala 1:50.000 y publicado a finales de la década (Antolín, 1998). Esta documentación cartográfica y base de datos asociadas en formato digital presentaba una serie de problemas que hicieron necesaria su adaptación en los siguientes aspectos:

- Mejora de la exactitud geométrica. Las deficiencias derivadas de la escala y de los errores en la digitalización de la cartografía original, fueron reducidas con la revisión de los límites de las unidades fisiográficas sobre las imágenes de 1984 y 2012 y un Modelo Digital de Elevaciones del PNOA (resolución 5x5 m).

- Correcciones en la exactitud temática y temporal. Se ha modificado la delimitación de las unidades cuyas coberturas del suelo anulan la capacidad agrológica del medio edáfico (superficies artificiales, zonas de extracción o vertido y masas de agua).

Para caracterizar la dinámica espacio-temporal de cambio de los usos y las coberturas del suelo resulta fundamental la construcción de un sistema de indicadores que aporten información sintética de las tendencias de cambio pro- 
vocadas por procesos de degradación, así como las modificaciones en el estado de los recursos naturales, aportando un tipo de información útil en el proceso de toma de decisiones y en la propuesta de estrategias de desarrollo sostenible (Recatalá et al., 2009). En este trabajo, se presentan los resultados de 12 indicadores aplicados en el municipio de Valencia, agrupados en diferentes áreas temáticas: "áreas construidas"; "consumo de suelo por la expansión urbana"; "transformación de áreas agrícolas y naturales"; "población, y densidad urbana" (cuadro 2).

\section{Cuadro 2}

INDICADORES APLICADOS EN EL MUNICIPIO DE VALENCIA, AGRUPADOS POR FECHA O PERIODO DE ANÁLISIS

\begin{tabular}{lrrrrc}
\hline \multicolumn{1}{c}{ Indicador $(*)$} & 1956 & 1984 & 2006 & 2012 & \\
\hline Superficie construida (AC) & 2.007 & 3.526 & 4.385 & 4.460 & ha \\
Porcentaje de superficie construida (AC) & 15,0 & 26,3 & 32,7 & 33,2 & $\%$ \\
Tipos de superficies construidas (AC) & & & & & \\
$\quad$ + Porcentaje de zonas residenciales & 83,7 & 78,5 & 79,1 & 79,1 & $\%$ \\
$\quad$ + Porcentaje de zonas industriales & 6,4 & 9,9 & 9,5 & 8,5 & $\%$ \\
$\quad$ Porcentaje de zonas de transporte & 9,9 & 11,5 & 11,5 & 12,4 & $\%$ \\
Porcentaje de zonas urbanas de alta y baja densidad (DU) & & & & & \\
$\quad$ + Porcentaje de zonas de alta densidad & 86,1 & 90,1 & 91,2 & 91,0 & $\%$ \\
$\quad$ Porcentaje de zonas de baja densidad & 13,9 & 9,9 & 8,8 & 10,1 & $\%$ \\
Densidad demográfica (PO) & 3.774 & 5.434 & 6.000 & 5.938 & $\mathrm{hab} / \mathrm{km} 2$ \\
Superficie construida disponible por persona (DU) & 39,6 & 48,3 & 54,4 & 56 & $\mathrm{~m} 2 / \mathrm{hab}$ \\
\hline
\end{tabular}

1956-2012 1956-1984 1984-2006 2006-2012

\begin{tabular}{lrrrrc}
\hline Crecimiento total de la superficie construida (AC) & 122,2 & 75,7 & 24,4 & 1,7 & $\%$ \\
Crecimiento anual de la superficie construida (AC) & 43,8 & 54,2 & 39 & 12,5 & ha/año \\
Pérdida de áreas naturales y agrícolas (CS) & 2396 & - & - & - & ha \\
$\quad$ + Pérdida de zonas agrícolas & 2244 & - & - & - & ha \\
$\quad$ + Pérdida de zonas naturales & 152 & - & - & - & ha \\
Abandono de zonas agrícolas (TA) & 7,2 & 3,3 & 5,8 & 5,2 & $\%$ \\
$\quad$ + Porcentaje de z. agrícolas abandonadas & 4,6 & 1,9 & 4,4 & 4,3 & $\%$ \\
$\quad$ Porcentaje de z. agrícolas regeneradas o reforestadas & 2,7 & 1,4 & 1,3 & 0,9 & $\%$ \\
Crecimiento de la población (PO) & 57,3 & 44 & 10,4 & -1 & $\%$ \\
\hline
\end{tabular}

1984-2012

Pérdida de suelos con elevada y muy elevada capacidad de uso (CS)

952

ha

* Entre paréntesis, áreas temáticas: AC- Áreas construidas; CS- Consumo de suelo; TA- Transformaciones de áreas agrícolas y naturales; PO- Población; DU- Densidad urbana. 
El primer grupo de indicadores se centra en la medida de elementos relacionados con la extensión y el crecimiento de las superficies construidas. Se contabilizan las magnitudes absolutas y relativas y se determina el rango y el ritmo de la dinámica. Además de contabilizar los porcentajes relativos para cada tipo de superficie construida, también se plasman el estado y las tendencias de mayor o menor dispersión y densidad que ha experimentado el uso urbano residencial. El segundo y tercer grupo de indicadores reflejan el consumo de suelo ocasionado por las superficies construidas. Se determina, así, tanto el carácter agrícola o forestal de los usos antecedentes, como la cantidad de suelos con una capacidad de uso elevada o muy elevada que han desaparecido a consecuencia del proceso de sellado. Los indicadores sobre población aportan información de especial relevancia sobre el que es, sin duda, uno de los principales factores de cambio y transformación de los usos del suelo. Siguiendo esa línea, otro grupo ("densidad urbana») hace hincapié en la relación existente entre la dinámica demográfica y el crecimiento de la superficie construida. La definición, la fuente y el procedimiento de cálculo para la elaboración de los indicadores puede consultarse en Valera et al. (2011).

\section{RESULTADOS Y DISCUSIÓN}

\section{Usos y coberturas del suelo a mediados del siglo xx. La situación en 1956}

En 1956 la superficie construida se reducía al centro histórico, los dos ensanches burgueses de finales del XIx e inicios del xx, los Poblados Marítimos y algunos núcleos aislados. Los valores de las superficies artificiales eran, ya en la fecha inicial de análisis, bastante elevados (figura 2), aspecto que se relaciona con la centralidad de la ciudad tanto a nivel metropolitano como regional.

En total las coberturas artificiales representaban 2.178 ha, de las cuales 2.007 ha eran superficies construidas, un porcentaje respecto a la superficie de referencia (13.422 ha) del 16,2\%. Las zonas urbanas constituían el componente más substancial de este gran grupo, concentrándose en torno al centro histórico y, de forma tentacular, junto a las principales vías de comunicación, con algunos núcleos urbanos correspondientes a pedanías, tanto al norte como al sur de la ciudad. Los poblados marítimos de El Cabanyal y Nazaret, así como el propio Puerto Autónomo, suponían la concentración secundaria de mayor importancia. Con una población municipal de más de medio millón de habitantes (figura 3), ya en esta fecha la densidad demográfica era muy elevada, con 3.774 hab. $/ \mathrm{km}^{2}$, y la superficie construida por habitante relativamente baja con $39,6 \mathrm{~m}^{2} / \mathrm{hab}$. 
FIGURA 2

USOS DEL SUELO EN 1956, 1984 Y 2012 (NIVEL 1)

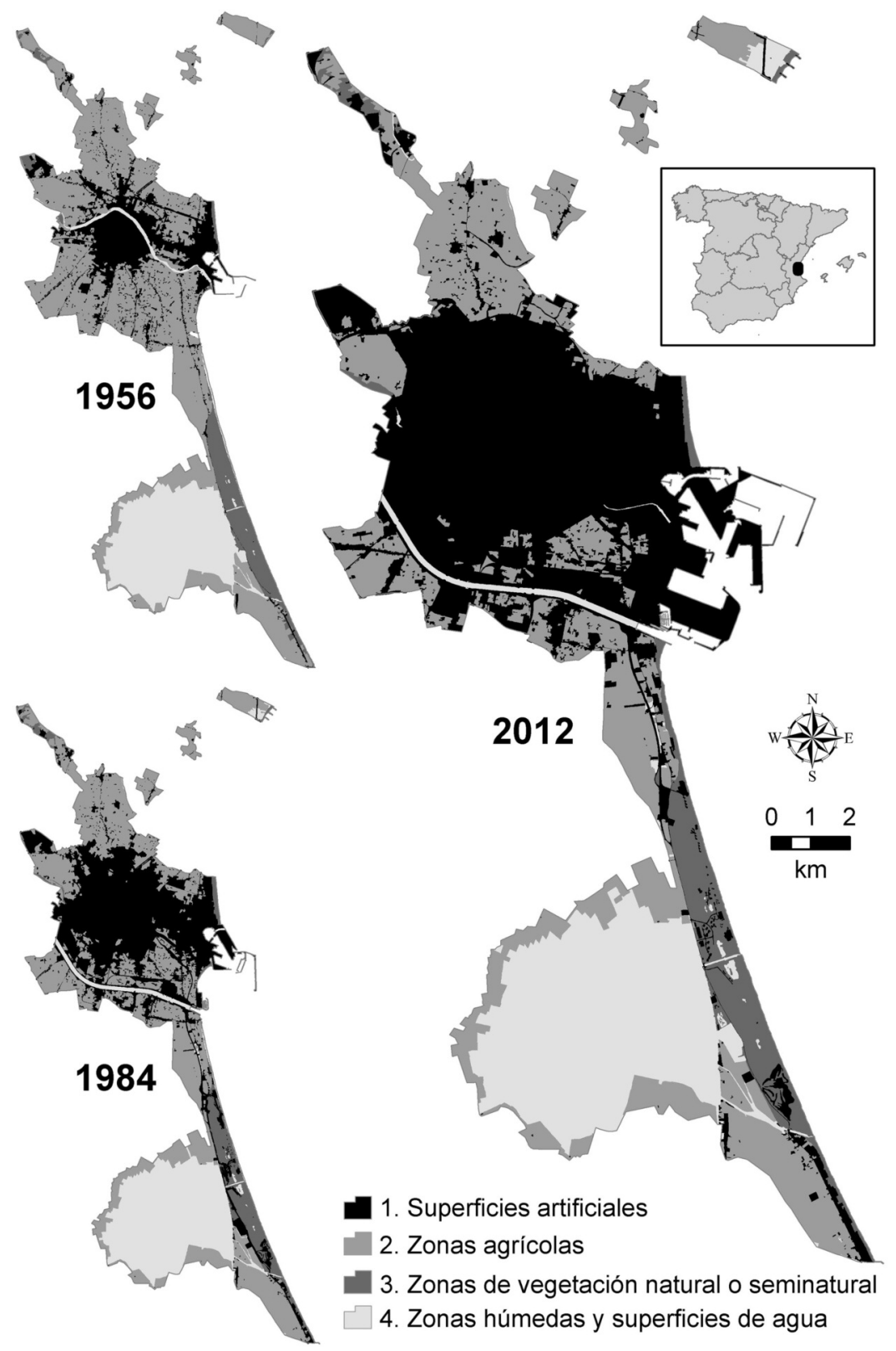

Estudios Geográficos, Vol. LXXVII, 281, pp. 671-692, julio-diciembre 2016 ISSN: 0014-1496, eISSN: 1988-8546, doi: 10.3989/estgeogr.201623 
FIGURA 3

EVOLUCIÓN DE LA POBLACIÓN MUNICIPAL (1900-2014)

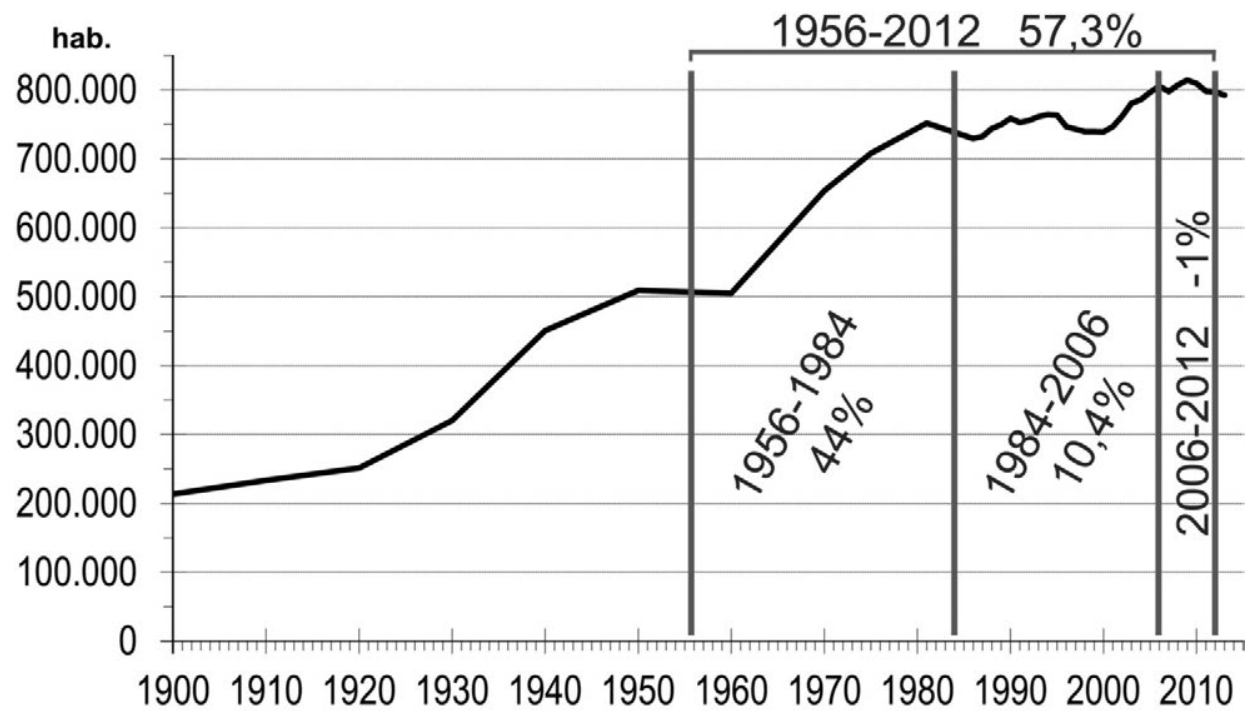

Fuente: Instituto Valenciano de Estadística.

Dentro de la tipología de superficies construidas predominaban las zonas residenciales $(83,7 \%)$, principalmente de alta densidad edificatoria. Las zonas industriales y comerciales $(6,4 \%)$ se yuxtaponían con las infraestructuras portuarias y ferroviarias, en su mayoría imbricadas en la trama urbana. Las superficies dedicadas a las infraestructuras de comunicación suponían un 9,9\%. Los solares urbanos, por su parte, aparecen en las áreas periféricas de la ciudad más fragmentadas ocupando únicamente 100 ha.

Si observamos las áreas no construidas disponibles, predominaban las zonas agrícolas, con 7.299 ha frente a las 3.813 ha de zonas naturales (usos forestales y masas de agua). Los cultivos en regadío acumulaban, casi en su totalidad, esa superficie agrícola, aprovechando el sistema de regadío tradicional (Hermosilla, 2007). Los cultivos herbáceos (5.148 ha), esencialmente hortícolas y destinados al mercado local, se distribuían en torno a la ciudad. Los arrozales (1.833 ha) coincidían con los marjales de l'Albufera y de Rafalell y Vistabella, esta última situada en la pedanía al noreste del municipio y que era casi inexistente en 1956 por la propia presencia del arrozal. Este tipo de utilización aprovechaba las particularidades edáficas de los marjales. Los suelos 
predominantes son Gleysoles calcáricos, marcados por el hidromorfismo que genera un drenaje imperfecto. Su capacidad de uso es moderada pero presenta unas características muy adecuadas para cultivar arroz (Añó et al., 2002). En estas zonas las transformaciones antrópicas estarán originadas por el aterramiento y drenaje para su conversión en huerta; el impacto del proceso urbanizador será muy limitado. Los leñosos en regadío, dispersos por los sectores noroccidental y suroccidental, tenían escasa presencia (200 ha) y correspondían principalmente a cítricos. Por último, los secanos (71 ha) estaban restringidos a un pequeño sector al noroeste.

Las superficies naturales o seminaturales (1.045 ha) concordaban con la franja litoral, a lo largo de la Devesa de l'Albufera. La tipología se subdividía en 361 ha de playas y dunas, 415 ha de vegetación arbustiva y/o herbácea y 268 ha de bosques. Por lo que respecta a zonas húmedas y superficies de agua (2.900 ha) correspondían casi en su totalidad al lago y el marjal de l'Albufera. También se incluía en esta clase el curso natural del río Túria (132 ha), que todavía discurría por su antiguo cauce, al norte del centro histórico de la ciudad.

\section{El periodo desarrollista e inicios de la Democracia. Usos del suelo en 1984}

El boom económico y demográfico del periodo 1960-1975 constituye el factor fundamental a la hora de entender las transformaciones posteriores (Sorribes, 1998). Aunque la concentración de habitantes y actividades continúo durante toda esta, parte se desvió a los municipios cercanos, extendiéndose de forma progresiva a una distancia cada vez mayor respecto al centro metropolitano, a causa de las mejoras en las comunicaciones y el incremento de la movilidad intermunicipal (Salom et al., 1995; Albertos et al., 2007).

Tras la riada de 1957, la llamada «Solución Sur» con la creación de un nuevo cauce para el Túria supondría en el futuro, además del proceso de conversión de suelo rústico a urbano por las características intrínsecas a la propia obra (cauce, accesos y enlaces viarios que lo circundan), una barrera y un nuevo límite para la ciudad (Teixidor, 1980). Así, la presencia del nuevo cauce, la cercanía de los municipios circundantes y el rápido y constante aumento de la población hicieron que el frente de urbanización fuese devorando progresivamente los espacios agrícolas de huerta y modificando el tradicional modelo urbano de estructura radioconcéntrica. El planeamiento vigente en la época, además, era en general permisivo con las actuaciones que se realizaban al margen de la normativa urbanística (Teixidor, 1982). 


\section{Cuadro 3}

USOS DEL SUELO 1956-2012 EN EL MUNICIPIO DE VALENCIA (EN HECTÁREAS)

\begin{tabular}{|c|c|c|c|c|c|c|}
\hline NIVEL 1 & NIVEL 2 & NIVEL 3 & 1956 & 1984 & 2006 & 2012 \\
\hline \multirow{13}{*}{$\begin{array}{l}\text { 1. Superficies } \\
\text { artificiales }\end{array}$} & 1.1. Zonas urbanas & $\begin{array}{l}\text { 1.1.1. Zonas urbanas de alta densidad } \\
\text { 1.1.2. Zonas urbanas de baja densidad }\end{array}$ & $\begin{array}{r}1.446 \\
234\end{array}$ & $\begin{array}{r}2.494 \\
274\end{array}$ & $\begin{array}{r}3.160 \\
306\end{array}$ & $\begin{array}{r}3.210 \\
319\end{array}$ \\
\hline & \multirow{3}{*}{$\begin{array}{l}\text { 1.2. Zonas Industriales, } \\
\text { comerciales } \\
\text { y militares }\end{array}$} & 1.2.1. Zonas industriales & 108 & 284 & 294 & 254 \\
\hline & & 1.2.2. Zonas comerciales & 0 & 44 & 101 & 103 \\
\hline & & 1.2.3. Zonas militares & 21 & 22 & 21 & 21 \\
\hline & \multirow{3}{*}{$\begin{array}{l}\text { 1.3. Infraestructuras } \\
\text { de comunicación }\end{array}$} & 1.3.1. Redes viarias y terrenos asociados & 39 & 209 & 241 & 295 \\
\hline & & $\begin{array}{l}\text { 1.3.2. Redes ferroviarias y terrenos } \\
\text { asociados }\end{array}$ & 73 & 98 & 136 & 151 \\
\hline & & 1.3.3. Zonas portuarias & 86 & 100 & 126 & 107 \\
\hline & \multirow{4}{*}{$\begin{array}{l}\text { 1.4. Zonas mineras, } \\
\text { vertederos y } \\
\text { en transformación }\end{array}$} & 1.4.2. Áreas en construcción & 22 & 41 & 298 & 87 \\
\hline & & 1.4.3. Áreas en transformación & 2 & 139 & 1 & 0 \\
\hline & & 1.4.4. Vertederos y escombreras & 0 & 0 & 0 & 11 \\
\hline & & 1.4.5. Solares urbanos & 100 & 474 & 336 & 515 \\
\hline & 1.5. Zonas verdes & 1.5.1. Zonas verdes urbanas & 48 & 90 & 272 & 326 \\
\hline & y espacios de ocio & 1.5.2. Campos de golf & 0 & 37 & 40 & 40 \\
\hline \multirow{6}{*}{$\begin{array}{l}\text { 2. Zonas } \\
\text { agrícolas }\end{array}$} & $\begin{array}{l}\text { 2.1. Cultivos } \\
\text { en secano }\end{array}$ & 2.1.2. Cultivos leñosos en secano & 71 & 22 & 0 & 0 \\
\hline & \multirow{4}{*}{$\begin{array}{l}\text { 2.2. Cultivos } \\
\text { en regadío }\end{array}$} & 2.2.1. Arrozales & 1.833 & 1.572 & 1.545 & 1.504 \\
\hline & & $\begin{array}{l}\text { 2.2.2. Cultivos herbáceos en regadío } \\
\text { (hortícolas) }\end{array}$ & 5.148 & 3.004 & 1.652 & 1.609 \\
\hline & & 2.2.3. Cultivos leñosos en regadío & 200 & 510 & 686 & 506 \\
\hline & & 2.2.4. Invernaderos & 2 & 31 & 61 & 58 \\
\hline & $\begin{array}{l}\text { 2.3. Otras superficies } \\
\text { agrícolas }\end{array}$ & 2.3.1. Cultivos abandonados & 45 & 144 & 235 & 345 \\
\hline \multirow{3}{*}{$\begin{array}{l}\text { 3. Zonas de } \\
\text { vegetación } \\
\text { natural o } \\
\text { seminatural }\end{array}$} & $\begin{array}{l}\text { 3.1. Formaciones } \\
\text { arboladas }\end{array}$ & 3.1.1. Bosques de pinos & 268 & 361 & 355 & 355 \\
\hline & $\begin{array}{l}\text { 3.2. Formaciones } \\
\text { no arboladas }\end{array}$ & $\begin{array}{l}\text { 3.2.2. Vegetación arbustiva } \\
\text { y/o herbácea }\end{array}$ & 415 & 222 & 217 & 217 \\
\hline & $\begin{array}{l}\text { 3.3. Z. con escasa } \\
\text { o nula vegetación }\end{array}$ & 3.3.1. Playas y dunas & 361 & 290 & 277 & 279 \\
\hline \multirow{4}{*}{$\begin{array}{l}\text { 4. Zonas } \\
\text { húmedas } \\
\text { y superficies } \\
\text { de agua }\end{array}$} & \multirow{3}{*}{$\begin{array}{l}\text { 4.1. Zonas húmedas } \\
\text { continentales }\end{array}$} & 4.1.1. Cursos de agua & 132 & 12 & 11 & 10 \\
\hline & & 4.1.2. Canales fluviales artificiales & 0 & 151 & 159 & 163 \\
\hline & & 4.1.3. Otras superficies de agua & 0 & 26 & 52 & 53 \\
\hline & $\begin{array}{l}\text { 4.2. Zonas húmedas } \\
\text { litorales }\end{array}$ & 4.2.1. Lagunas litorales / marjales & 2.768 & 2.770 & 2.841 & 2.885 \\
\hline
\end{tabular}


Así, en 1984 se constata un incremento considerable de las superficies construidas respecto a 1956 (cuadro 3), con un ritmo medio estimado de 54,2 ha/año. Las zonas residenciales, aunque mayoritarias dentro de este grupo $(78,5 \%)$, redujeron su representación porcentual ante las zonas industriales y comerciales $(9,9 \%)$ e infraestructuras de comunicación (11,5\%).

Las zonas agrícolas ( $5.283 \mathrm{ha}$ ) continuaron siendo predominantes en el municipio, aunque se redujeron tanto los cultivos de secano como, sobre todo, los de regadío frente al aumento de las superficies artificiales (4.306 ha). Los cultivos hortícolas continuaron siendo la tipología agrícola más representada, con 3.004 ha, seguido por la superficie de arrozal (1.572 ha). También retrocedieron la zonas de vegetación natural y seminatural, en gran medida a causa de un proyecto de los años 60 (que incluía entre otras cosas la construcción de hoteles, apartamentos, un hipódromo, un lago artificial o un campo de golf sobre la restinga de l'Albufera) con un gran impacto paisajístico y ambiental que han permanecido, en parte, hasta la actualidad (Fernández, 2003). Los humedales litorales o marjales (2.796 ha) se expandieron ligeramente a costa de áreas de arrozal, herbáceas en regadío y zonas de vegetación natural. La clase "canales fluviales artificiales", sin ninguna representatividad espacial en la fecha precedente, ocupaba en 1984 lo que fueron áreas de huerta antes de la gran riada de 1957 y la ejecución en las décadas de los 60 y 70 del ambicioso proyecto de minimización de daños por avenidas.

\section{Transformaciones durante la Democracia y el boom inmobiliario hasta el} año 2006

La ralentización del crecimiento económico y demográfico, iniciado a mediados de la década de los 70, y la instauración de la democracia hacían evidente la necesidad de un nuevo tipo de planeamiento que se concretó en el Plan General de Ordenación Urbana de 1988. Aunque con él se pretendían corregir los desequilibrios derivados de la planificación municipal anterior; la reactivación económica de finales de los años 80 provocó el incumplimiento de algunos de los objetivos iniciales, como la descalificación del exceso de suelo destinado a uso urbano o la protección efectiva de la huerta. Así, en el periodo 1984-2006 el aumento de la superficie construida fue del $24,4 \%$, en claro contraste con un crecimiento de la población considerablemente inferior al periodo anterior (marcado por la etapa desarrollista) y que representó $10,4 \%$. 
El crecimiento se localizó principalmente junto a áreas ya urbanizadas, de forma que las zonas urbanas (residenciales) ocuparon gran parte del sector central del municipio, presentando mayor continuidad espacial que en 1984. Las zonas en construcción, y los solares, con 298 ha y 336 ha respectivamente, son indicativas de la continuación del proceso de urbanización sobre espacios anteriormente agrícolas, con singular incidencia al sureste de la ciudad, en la nueva Zona de Actividades Logísticas (ZAL). Así, en dirección sur el proceso urbanizador progresó hasta el cauce nuevo del Túria, incluso superándolo en determinadas áreas, mientras que por el norte se alcanzó casi el límite con otros municipios. Continuó así la tendencia de ocupación de espacios intraurbanos, conformando una ciudad cerrada con una delimitación bien definida. Únicamente quedó una bolsa interior de huerta con cierta extensión entre el borde sudoeste de la ciudad, el puerto y el nuevo cauce del Túria. En líneas generales, y al igual que en otros municipios de la Comunidad Valenciana, se sobredimensionó la oferta de suelo urbanizable (Burriel, 2009a), gracias, en gran medida, a la ausencia de una planificación urbanística regional impulsada y coordinada por el gobierno autonómico (Burriel, 2011).

Por último, hay que mencionar el crecimiento de las zonas verdes urbanas, principalmente por la reconversión del antiguo cauce del Túria en parque urbano. Las áreas de cultivo se redujeron a 4.180 ha, retroceso de nuevo frente a las superficies artificiales, desapareciendo por completo en esta fecha los cultivos en secano. Además, los cultivos herbáceos disminuyeron ante los leñosos (cítricos) y las parcelas agrícolas abandonadas ( $254 \mathrm{ha}$ ) se localizaron en los sectores de mayor presión urbanística, especialmente entre el frente sur de la ciudad y el conjunto formado por el nuevo cauce del río y las infraestructuras anexas al mismo. Entre las escasas transformaciones experimentadas por la vegetación natural o seminatural destacó la regeneración o reconstrucción dunar en El Saler mediante, por ejemplo, el levantamiento del paseo marítimo, y los marjales, de poca relevancia espacial pero gran significación ecológica y paisajística. Mediante el Decreto 89/1986 del Consell de la Generalitat Valenciana el sistema constituido por el lago de La Albufera, el marjal que lo rodea y la restinga costera adquirió el régimen jurídico de Parque Natural, constituyéndose, por tanto, en un espacio protegido. El último ambiente, la Devesa, es el más complejo de los tres y el que sufrió mayor alteración antrópica. Los suelos más representativos (Arenosoles calcáricos) tienen una capacidad agrológica baja o muy baja. Son suelos no evolucionados, por tanto con un perfil prácticamente indiferenciado, y de textura arenosa. Esta característica granulométrica influye directamente en sus desfavorables características físicas y 
químicas: baja capacidad de retención de agua, baja estabilidad estructural, escaso contenido en materia orgánica y reducida capacidad de cambio (Añó et al., 2002).

\section{La dinámica tras la ruptura de la burbuja. Usos/coberturas del suelo en 2012}

En 2012 un total de 4.460 ha corresponden a superficies construidas, crecimiento que se localiza principalmente en el sector central del municipio, rellenando las edificaciones residenciales (79\% del total) los espacios que permanecían sin construir alrededor de la ciudad e incrementándose la superficie destinada a las infraestructuras de comunicación en los ejes de acceso desde el oeste. El porcentaje de zonas de transporte se incrementó respecto a 2006, ampliándose las infraestructuras viarias preexistentes y también las ferroviarias por la construcción del Tren de Alta Velocidad (AVE).

Los solares urbanos (512 ha) se expandieron, estando constituidos en su mayoría por espacios ya urbanizados pero en los que no se había iniciado la edificación. Las zonas verdes urbanas se incrementaron también, siendo uno de los pocos elementos consolidados dentro de los planes urbanísticos que permanecen sin edificar aún en la actualidad. En este sentido, las áreas en construcción se redujeron respecto a 2006.

Tanto los cultivos hortícolas como los leñosos vieron reducida su superficie, expandiéndose por el contrario los cultivos abandonados principalmente junto a las nuevas vías de comunicación y en la franja comprendida entre el frente sur de la ciudad y el nuevo cauce del río Túria. Precisamente esa reserva de huerta fue una de las áreas más afectadas por el crecimiento urbano del periodo 2006-2012, viéndose progresivamente reducida por las áreas en construcción en la Ronda Sur y la ZAL, así como la degradación de espacios agrícolas vinculada a la entrada a la ciudad del AVE. En este sentido, la crisis económica iniciada en 2008 ha dejado en esta franja amplios espacios urbanizados pero no construidos, con nuevas zonas verdes que, pese a sus ventajas, suponen para la ciudad un incremento de gasto público que no se ve compensado por los ingresos derivados de usos residenciales o terciarios en parcelas que únicamente contienen solares urbanos sin construir.

La construcción ha supuesto una pérdida considerable de áreas agrícolas y naturales, que en conjunto se cuantifica en 2.396 ha. De ellas, la mayor parte corresponde a zonas agrícolas, con 2.244 ha frente a las 152 ha de zonas naturales. Además, buena parte de la superficie sellada afecta a suelos de gran ferti- 
lidad. Desde un punto de vista edáfico la unidad taxonómica mayoritaria corresponde a Fluvisoles calcáricos. Estos suelos, presentes en toda la llanura de inundación del río Turia, se desarrollan en superficies llanas y muestran muy poca diferenciación en su perfil aunque, morfológicamente, existan discontinuidades litológicas consecuencia de diferentes aportes fluviales. En estos suelos carbonatados el espesor efectivo es elevado, la pedregosidad superficial escasa, la permeabilidad y la porosidad son muy altas, la aireación es buena, la textura suele ser equilibrada, el pH básico, la salinidad es baja y los contenidos en materia orgánica, nitrógeno y fósforo son, en general, bajos. En conjunto son suelos con muy elevada capacidad de uso agrario (Añó et al., 2002). Estos suelos constituyen las mejores áreas de dedicación agrícola, ya que la falta de humus se palía generalmente con abonado. Las limitaciones principales están provocadas por la sobreexplotación de los acuíferos que, dada su proximidad a la costa, pueden inducir la salinización del perfil edáfico por intrusión marina. Durante el periodo 1984-2012 se destruyeron 952 ha de suelos con elevada y muy elevada capacidad de uso. Estos suelos sellados se han destinado mayoritariamente a usos residenciales (695 ha), siendo la superficie destinada a infraestructuras de 143 ha y a usos industriales y comerciales de 114 ha (figura 4).

\section{A modo de síntesis. Más de medio siglo (1956-2012) de transformaciones en el municipio de valencia}

El análisis de la evolución de los usos y coberturas del suelo en el municipio de Valencia entre 1956 y 2012 mediante el cruce de las capas cartográficas de distintas fechas y la aplicación de los indicadores propuestos, pone de relieve una dinámica de progresiva sustitución de los usos agrícolas y naturales del suelo frente a las superficies construidas (cuadro 4).

La capitalidad regional de la ciudad de Valencia se ha reflejado en una creciente presión demográfica en el municipio, principal receptor del flujo inmigratorio en toda la provincia debido a su papel de centro de servicios y temprana industrialización (Prytherch y Boira, 2009). Un crecimiento poblacional del 57,3\% entre 1956 y 2012 ha provocado que la densidad de población ronde en esta última fecha los $6.000 \mathrm{hab} . / \mathrm{km}^{2}$ y esa progresiva presión antrópica ha provocado que la distribución de usos del suelo haya cambiado significativamente en 56 años. La transformación fundamental ha consistido, sobre todo, en el retroceso de las zonas agrícolas. Así, éstas representaban en 1956 un total de 7.299 ha, en 2012 esa mismas clase se ha reducido hasta las 


\section{FIGURA 4}

CRECIMIENTO DE LA SUPERFICIE CONSTRUIDA DURANTE EL PERIODO 1956-2012

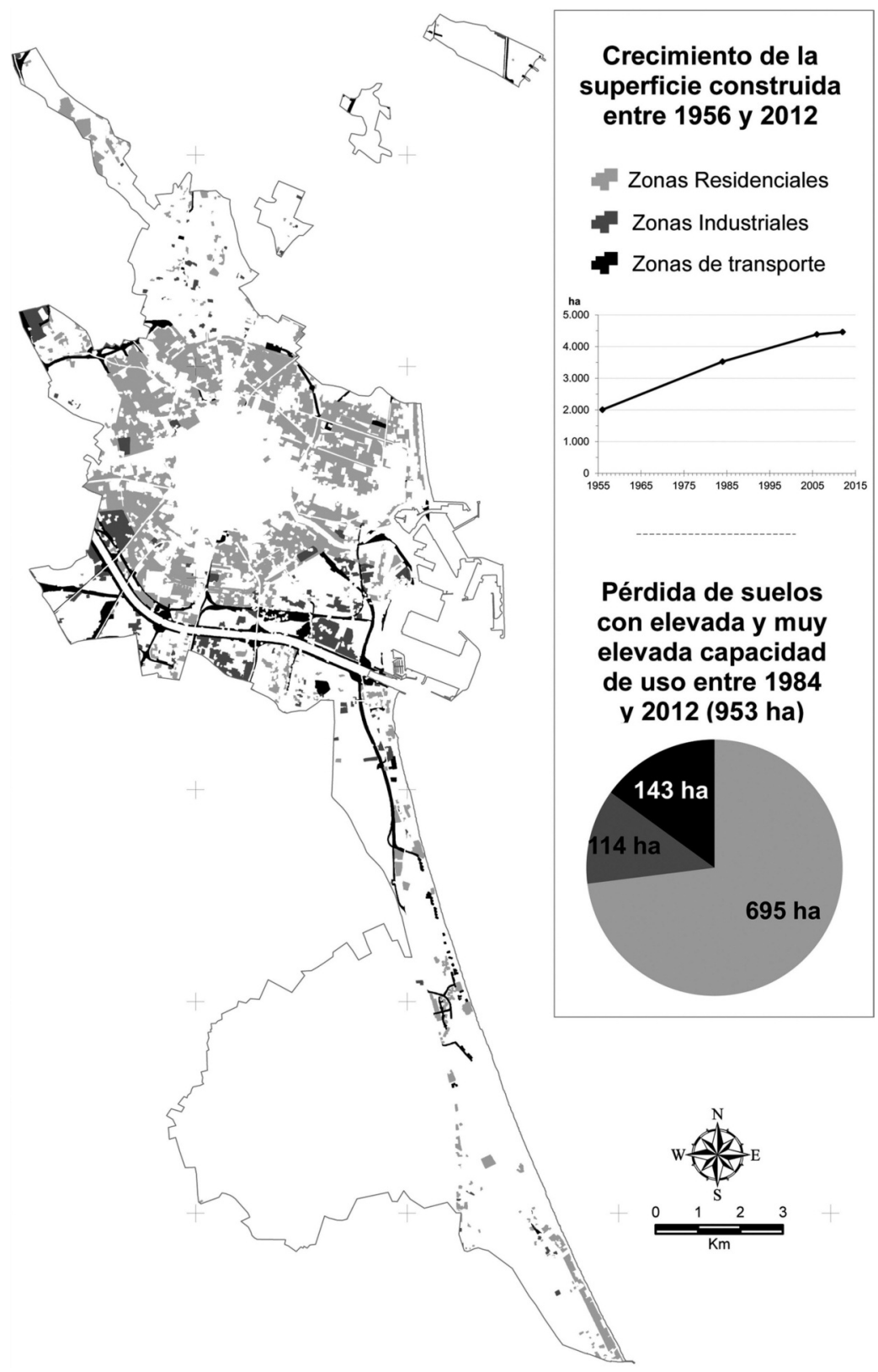

Estudios Geográficos, Vol. LXXVII, 281, pp. 671-692, julio-diciembre 2016 ISSN: 0014-1496, eISSN: 1988-8546, doi: 10.3989/estgeogr.201623 


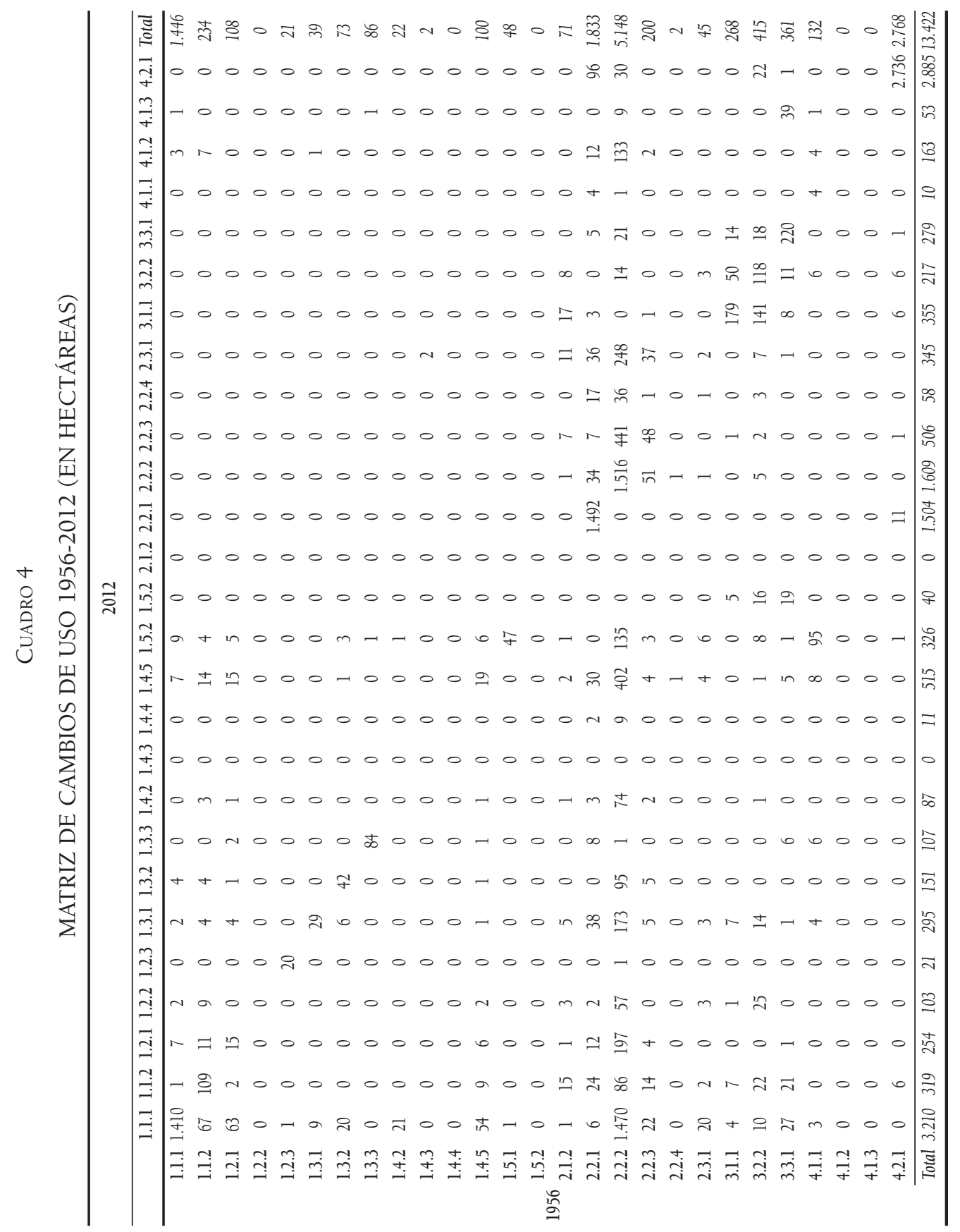

Estudios Geográficos, Vol. LXXVII, 281, pp. 671-692, julio-diciembre 2016 ISSN: 0014-1496, eISSN: 1988-8546, doi: 10.3989/estgeogr.201623 
4.022 ha. Las áreas naturales han disminuido ligeramente, pasando de las 3.813 ha iniciales hasta las 3.736 ha de la fecha final.

Dentro de los cambios intrínsecos de las áreas agrícolas y naturales, destaca la total desaparición de los cultivos de secano que se localizaban en 1956 en el sector noroccidental del municipio. La transformación dentro de los cultivos en regadío no aparece tan clara, si bien se ha producido un cierto incremento en el porcentaje de leñosos (cítricos) frente a herbáceos (huerta). Por otra parte, dejando al margen la urbanización de zonas agrícolas, un $7,2 \%$ de las áreas cultivadas en 1956 ha sido abandonada $(4,5 \%)$ o regenerada por la vegetación natural $(2,7 \%)$ en 2012. Como contrapunto, el crecimiento de la superficie construida durante todo el periodo representa un $122 \%$, con un ritmo medio anual de construcción de 43,8 ha/año.

Tal y como señala Burriel (2009a y 2009b), la insostenibilidad del planeamiento urbanístico municipal, las carencias o insuficiencias del ordenamiento territorial supramunicipal y la ausencia de medidas limitadoras del crecimiento en las sucesivas modificaciones de la legislación autonómica, han propiciado la desmesurada expansión urbanística en la Comunitat Valenciana, aspectos todos ellos a la que no ha sido ajeno el municipio de Valencia. La burbuja inmobiliaria y las expectativas urbanísticas han restado racionalidad a la planificación urbana y promovido, directa o indirectamente, la proliferación de usos del suelo transicionales como solares urbanos, cultivos abandonados o áreas en construcción. Así, es importante conocer los datos detallados de cambios de usos del suelo y de sellado del medio edáfico para que pueda ser tenida en cuenta esta variable en el diseño de una planificación urbanística municipal orientada a la integración de la ciudad con su entorno agrícola tradicional y representativo que, sin lugar a dudas, es la huerta.

\section{CONCLUSIONES}

La relevancia de las transformaciones de usos y coberturas del suelo, y especialmente el sellado antropogénico derivado del crecimiento de las superficies artificiales en el municipio de Valencia entre 1956 y 2012 ha sido muy elevada. Hay que considerar que el área todavía no sellada incluye espacios de elevado valor ambiental (marjales o zonas húmedas litorales), que han recibido por ello algún tipo de figura de protección. Además, el crecimiento urbano se ha desarrollado mayoritariamente sobre suelos con elevada y muy elevada capacidad de uso, capaces de sostener durante siglos una intensa y productiva actividad agrícola. 
Aunque la urbanización se relaciona en gran medida con la dinámica demográfica, la diferencia entre las tasas de crecimiento de la población $(57,3 \%)$ y de las superficies construidas (122,2\%) indica un cambio en las pautas de ocupación del territorio para los distintos usos y especialmente los urbanos. La superficie construida disponible por habitante ( $56 \mathrm{~m}^{2} / \mathrm{hab}$.), aunque elevada, es inferior a la cuantificada en otros espacios urbanos metropolitanos de la Comunidad Valenciana (Valera, 2011), caracterizados por una urbanización más extensiva que la de la ciudad mediterránea tradicional.

No obstante, el crecimiento de la superficie urbanizada ha implicado la pérdida de 2.244 ha de áreas agrícolas. La suspensión, en 2010, del Plan de Acción Territorial de la Huerta de Valencia (promovido por la Generalitat Valenciana), que contemplaba la limitación de la expansión de las áreas urbanas metropolitanas y la potenciación de los usos agrícolas tradicionales, ha hecho que se mantenga la vulnerabilidad de la huerta y de los suelos sobre los que se asienta ante la posible reactivación de los procesos especulativos de urbanización que han afectado en las últimas décadas a todo el país y especialmente a la Comunitat Valenciana. Desde este último punto de vista, un reciente estudio (Romero y Melo, 2015) defiende la necesidad de recuperar el Plan de Acción Territorial de la Huerta promoviendo, políticamente, su desarrollo e involucrando a los municipios afectados.

\section{BIBLIOGRAFÍA}

AEMA (1998): Medio ambiente en Europa. El Informe Dobrís, Luxembourg, Agencia Europea de Medio Ambiente.

Albertos, J. M., Noguera, J., Pitarch, M. D. y Salom, J. (2007): "La movilidad diaria obligada en la Comunidad Valenciana entre 1991 y 2001: Cambio territorial y nuevos procesos", Cuadernos de Geografía, 81-82, pp. 93-118.

Antolin, C. (coord.) (1998): El Suelo como Recurso Natural en la Comunidad Valenciana, Valencia, COPUT, Generalitat Valenciana, 187 pp. Colección Territori 8.

Añó, C., Sánchez, J., Antolín, C. y Goberna, M. (2002): "Capacidad y vulnerabilidad de los suelos de la Comunidad Valenciana”, Investigaciones Geográficas, 28, pp. 105-123.

Burriel, E. (2009a): "Los límites del planeamiento urbanístico municipal. El ejemplo valenciano", Documents d'Anàlisi Geogràfica, 54, pp. 33-54.

Burriel, E. (2009b): "La planificación territorial en la Comunidad Valenciana (19862009)", Scripta Nova. Revista Electrónica de Geografía y Ciencias Sociales, XIII/30, http://www.ub.es/geocrit/sn/sn-306.htm (Fecha de consulta: 31/4/2015).

Burriel, E. (2011): "Subversion of land-use plans and the housing bubble in Spain", Urban Research and Practice, 4, pp. 232-249. 
EEA (2010): The European Environment - State and Outlook 2010: Land Use, Copenhagen, European Environment Agency.

Fernández, A. (2003): "Ordenación del frente litoral de la Albufera. Sector Dehesa de El Saler, Valencia”, Ciudades, 7, pp. 145-149.

Furió, A. (2012): "La ciudad y la Huerta: una relación de interdependencia", en J. Romero y M. Francés (eds.), La Huerta de Valencia. Un paisaje cultural con futuro incierto, Valencia, Universitat de València, pp. 33-54.

Hermosilla, J. (2007): El patrimonio hidráulico del Bajo Turia: l'Horta de València, Valencia, Generalitat Valenciana, 461 pp. Regadíos históricos valencianos, 9.

IGN (2011): Sistema de Información de Ocupación del Suelo en España, Documento Técnico SIOSE 2005, Instituto Geográfico Nacional.

Lasanta, T., Nadal-Romero, E., Gómez-Villar, A. y Serrano-Muela, P. (2014): "Los estudios sobre cambios de gestión y ocupación del suelo en la montaña española cuarenta años después", en J. Arnáez, P. González, T. Lasanta y B. L. Valero (eds.), Geoecología, Cambio Ambiental y Paisaje: Homenaje al Profesor José María GarcíaRuiz, Zaragoza, CSIC, pp. 349-370.

Martínez Fernández, J., Ruiz Benito, P. y Zavala, M. A. (2015): "Recent land cover changes in Spain across biogeographical regions and protection levels: Implications for conservation policies", Land Use Policy, 44, pp. 62-75.

Membrado, J. C. (2011): "SIOSE Valencia 2005: resultados, aplicaciones y comparación con CORINE", Cuadernos de Geografía, 89, pp. 1-22.

Prytherch, D. L. y Boira, J. V. (2009): “City profile: Valencia”, Cities, 26, pp. 103-115.

Puncel, A. (1999): "Valencia: opciones, desorden y modernidad, o la ciudad que se devora a sí misma", Scripta Nova. Revista Electrónica de Geografía y Ciencias Sociales, 47, http://www.ub.es/geocrit/sn-47.htm (Fecha de consulta: 31/4/2015).

Recatalá, L., Añó, C., Valera, A. y Sánchez, J. (2009): "Sistema de indicadores para evaluar la calidad ambiental y la desertificación en la Comunidad Valenciana", Investigaciones Geográficas, 50, pp. 5-18.

Romero, J. y Melo, C. (2015): "Spanish Mediterranean Huertas: theory and reality in the planning and management of peri-urban agricultural and cultural landscapes", WIT Transactions on Ecology and The Environment, 193, pp. 585-595.

Salom, J., Delios, E., Pitarch, M., Pérez, J. y Albertos, J. M. (1995): "La formación de una segunda Corona Metropolitana en torno a la ciudad de Valencia: la movilidad por motivos de trabajo en la Comarca del Camp de Túria", Estudios Geográficos, LVI/221, pp. 711-735.

Sanchis, C. (2007): "LAlbufera de Valencia: sistema natural y producto humano", en ECO-RICE, Arroz en el Parque Natural de l'Albufera, un futuro sostenible, Valencia, Generalitat Valenciana, pp. 9-29.

Serra, P., Pons, X. y Saurí, D. (2008): "Land-cover and land-use change in a Mediterranean landscape: A spatial analysis of driving forces integrating biophysical and human factors", Applied Geography, 28, pp. 189-209.

Serra, P., Vera, A., Tulla, A. F. y Salvati, L. (2014): "Beyond urban-rural dichotomy: Ex- 
ploring socioeconomic and land-use processes of change in Spain (1991-2011)", Applied Geography, 55, pp. 71-81.

Sorribes, J. (1998): La ciutat desitjada. València entre el passat i el futur, Valencia, Tándem Edicions, 214 pp.

Teixidor, M. J. (1980): "Una lectura de la expansión urbana de Valencia: el modelo de crecimiento axial", Cuadernos de Geografía, 27, pp. 157-172.

Teixidor, M. J. (1982): València, la construcció d’una ciutat, Valencia, Institució Alfons el Magnánim, 144 pp.

Thomson, A., Manchester, S., Swetnam, R. D., Smith, G., Wadsworth, R. A., Petit, S. y Gerard, F. (2007): "The use of digital aerial photography and CORINE-derived methodology for monitoring recent and historic changes in land cover near UK Natura 2000 sites for the BIOPRESS project", International Journal of Remote Sensing, 28, pp. 5397-5426.

Valera, A. (2011): Dinámica espacio-temporal de usos y cubiertas del suelo en áreas metropolitanas de la Comunidad Valenciana, Valencia, Servei de Publicacions de la Universitat de València, 310 pp, http://hdl.handle.net/10803/78869.

Valera, A., Añó, C. y Sánchez, J. (2011): "Cambios en los usos y coberturas del suelo en el municipio de Elx (1956-2005)”, Estudios Geográficos, LXXII/271, pp. 681-703.

Fecha de recepción: 31 de marzo de 2015.

Fecha de aceptación: 25 de noviembre de 2015. 